Review Article

\title{
Cognitive behavioural therapy and pain coping skills training for osteoarthritis knee pain management: a systematic review
}

\author{
Ayah Ismail, MSc ${ }^{1)^{*}}$, Catherine Moore, $\mathrm{MSc}^{2)}$, Natasha Alshishani, $\mathrm{MSc}^{3)}$, \\ Khalid Yaseen, MSc ${ }^{1)}$, Mansour Abdullah Alshehri, $\mathrm{MSc}^{4}$ ) \\ 1) Department of Physical Therapy, Faculty of Applied Medical Sciences, King Abdul Aziz University: \\ Jeddah, Saudi Arabia \\ 2) Physiotherapy Division, School of Health Sciences, University of Nottingham, United Kingdom \\ 3) Connect Health, United Kingdom \\ 4) Physiotherapy Department, Faculty of Applied Medical Sciences, Umm Al-Qura University, Saudi \\ Arabia
}

\begin{abstract}
Purpose] To investigate the effectiveness of cognitive-behavioural therapy (CBT) and pain coping skills training (PCST) on pain level in adults with osteoarthritis of the knee (KOA) in comparison with usual care. [Subjects and Methods] Five databases were systematically searched for relevant randomised controlled trials (RCTs) according to the selected eligibility criteria (inception to June 7, 2016). PEDro scale was used to assess the validity of included studies. [Results] Four studies met the inclusion criteria and all studies had high methodological quality. The total number of participants was 665 across the four included studies. All participants had been diagnosed with KOA (clinical and radiographic evaluation). The majority of the population were female (71.13\%). The interventions utilised were: CBT, CBT for insomnia (CBT-I), PCST, and PCST combined with behavioral weight management (BWM) in one study and with exercise in another study. The outcome measure for pain in KOA was the WOMAC scale. Overall, three studies have reported clinical improvement in KOA pain perception after 12-month follow-up time point. [Conclusion] This review has recognised the need for future studies that have rigorous methodological quality, and investigate the effect of mutual CBT and PCST protocols on KOA pain and pain-related functional and psychological abilities.

Key words: Osteoarthritis, Knee pain, Cognitive-behavioural therapy
\end{abstract}

(This article was submitted Aug. 19, 2017, and was accepted Sep. 29, 2017)

\section{INTRODUCTION}

Osteoarthritis (OA) is the most common form of arthritis, and one of the leading causes of pain and disability worldwide ${ }^{1)}$. Since OA is a chronic disease, an incident case continues to prevail for the remainder of the subject's life. The most commonly affected joint in the lower extremity is the $\mathrm{knee}^{2}$, with a lifetime prevalence for osteoarthritis of the knee (KOA) estimated to be $40 \%$ and $47 \%$ in Australian men and women respectively ${ }^{3}$. KOA is a global condition that affects more than 6 million persons in the United Kingdom alone, with lifetime prevalence approaching 50\% in the senior adult age group (over 80 years old $)^{4}$. Incidence reports show that women, older adults ( $\geq 45$ years), obese adults ( $\geq 30$ body mass index (BMI)) or patients with a previous history of knee injury have a moderate to strong increased risk of developing a symptomatic and radiographic confirmed $\mathrm{KOA}^{5,6}$.

Reduction in the quality of life and the development of disabling symptoms are chronic consequences of $\mathrm{KOA}^{7)}$. The most

*Corresponding author. Ayah Ismail (E-mail: anesmaeel@kau.edu.sa)

(C2017 The Society of Physical Therapy Science. Published by IPEC Inc.

(c) (1) $\odot$ This is an open-access article distributed under the terms of the Creative Commons Attribution Non-Commercial No DerivacC. 
frequently reported symptom of OA is pain. In 2003, a survey of 2,000 sufferers of OA found that $81 \%$ of them are in constant pain or experience limitations when performing everyday tasks ${ }^{2}$. Apart from experiencing pain, KOA patients tend to develop physical disabilities and experience joint problems including tenderness, stiffness and decrease in joint flexibility ${ }^{1)}$. One of the most commonly reported functional difficulties is walking ${ }^{8)}$. In addition, patients with KOA may experience considerable arthritis induced psychological problems that could intensify their existing pain and physical disabilities ${ }^{9)}$. Depression, anxiety, and helplessness are examples of the psychological problems that arthritis patients might develop ${ }^{10)}$. Additionally, poor pain coping strategies have been found to exacerbate physical disabilities and pain in KOA ${ }^{11)}$. Furthermore, KOA pain is a type of chronic pain that has been found to have variable and interconnected psychological aspects: emotional, cognitive and behavioural ${ }^{11,12)}$. Thus, when a negative emotional response to the illness arises, it may affect a patient's behavioural and the biological responses, and vice versa ${ }^{12)}$.

The National Collaborating Centre for Chronic Conditions noted the impact of psychological factors in cases of OA pain and disability and argued that psychological interventions can modify these problems to improve outcomes ${ }^{13)}$. Psychological management of OA is a relatively new endeavour, but it may have an influential impact on KOA patients' quality of life and serve as a promising therapy for specific OA population. KOA incidence data shows that KOA affects younger populations (45-65 years old), which means that they may live with disease for three decades or more ${ }^{14)}$. If this population educated about coping with pain and disease management from the onset, their quality of life could improve. Such interventions might benefit not only OA patients with chronic pain but also the more elderly and patients with multiple joint pathologies and uncommon OA patterns. Current OA management practices have not been proven to be efficient in controlling pain and improving quality of life ${ }^{1)}$.

To date, there is no panacea for OA. The aim of various interventions for OA is to control pain, improve joint function and minimise disability. Current approaches for KOA pain management demonstrated variable success rates, even for total knee replacement (TKR), which is currently deemed the most effective intervention ${ }^{9}$. Beswick et al. ${ }^{15}$ ) review revealed that $34 \%$ of patients who have undergone TKR continue to have chronic knee pain. Certain preoperative psychosocial factors (i.e. pain catastrophising and depression) were reasons for continued pain after TKR. Thus, an argument for addressing psychosocial factors in early KOA pain management exists. Adding psychological interventions to other approaches in KOA rehabilitation should be considered; although, Kittelson et al. ${ }^{9}$ argued, "our ability to incorporate this knowledge into the process of diagnosis, prognosis, and treatment remains a work in progress".

In 2007, Dixon et al. produced the most recent published systematic review (SR) of psychological interventions for OA ${ }^{16)}$. However, the majority of the trials included and appraised in Dixon et al.'s meta-analysis (Psychological Interventions for Arthritis Pain Management in Adults) concerned rheumatoid arthritis (RA). Although OA and RA are the most common types of arthritis, there are many differences between the two conditions (i.e. disease nature, progression, joints affected, symptoms and level of disability). Therefore, the outcomes of the interventions for RA cannot be generalised to OA. Moreover, that SR and meta-analysis comprised numerous and variable psychological interventions such as emotional disclosure, biofeedback training, stress management training, and hypnosis in addition to CBT and PCST. Although two-thirds of the included trials tested the efficacy of CBT and PCST for arthritis pain management, there is a need for focused investigation of these interventions on KOA, particularly given the high prevalence of KOA compared to other joints affected by OA.

The study of OA pain, psychological factors, and psychological management is a relatively new endeavour, despite the inclusion of $\mathrm{OA}$ in reviews that have investigated the psychological management of chronic pain conditions such as Morley et al.'s ${ }^{17)}$ systematic review. This review investigates the effectiveness of psychological interventions on KOA in depth by including and appraising high-quality research studies. Over the last few years, a number of randomised and pseudorandomised trials have studied the effectiveness of different psychological interventions on $\mathrm{KOA}^{18-20)}$. To date, these studies have not been appraised or reviewed systematically. Therefore, the purpose of this review is to investigate the effectiveness of cognitive-behavioural therapy (CBT) and pain coping skills training (PCST) on perceived pain level in adults with KOA in comparison with usual care.

\section{SUBJECTS AND METHODS}

This SR was performed in accordance with the Preferred Reporting Items for Systematic Review and Meta-Analysis (PRISMA) guidelines ${ }^{21)}$. Included articles for the review were located following a systematic search of the following electronic databases; MEDLINE (via Ovid), Psychinfo (via Ovid), EMBASE (via Ovid), CINAHL, and JBI from inception to June 7, 2016. Search terms included pain, osteoarthritis, knee, psychological therapy, cognitive therapy and pain coping. The bibliographies of the included studies were reviewed for further relevant citations. The search was limited to English Language papers only.

Studies were selected for review if they were RCTs testing the efficacy of CBT and PCST on KOA pain in adults. Multimodal interventions were included if they involved a component of cognitive therapy. For inclusion each study had to meet the following criteria: recruitment of an adult sample ( $>18$ years), radiographically diagnosed with unilateral or bilateral KOA, inclusion of the intervention either CBT or PCST and a measure of pain as an outcome measure. Either of the interventions had to be delivered directly from therapist to the patient (i.e. not to a patient's family member). The outcome chosen for this review was the Western Ontario and McMaster Universities osteoarthritis index (WOMAC) ${ }^{22}$. The reliability 
and validity of the WOMAC index is supported by several studies ${ }^{23-25)}$.

The eligibility criteria were applied to the title and abstract by two independent researchers (A.I. \& N.A.) to ensure agreement, with the retained articles cross-checked for duplicates (Endnote X7, Thomson Reuters). The full-text of the retained articles was independently screened according to the criteria; only articles that fulfilled the inclusion criteria were retained for the review. Where contrarieties in eligibility assessment existed this was first resolved by discussion between the two independent researchers (A.I \& N.A.) and the opinion of a third researcher (C.M.) sought if a consensus was not reached.

Studies that met the inclusion criteria were rated by two independent reviewers (A.I. \& N.A.) for methodologic quality using (the PEDro scale); developed by the Physiotherapy Evidence Database (PEDro) ${ }^{26}$. This scale was described as a highly reliable tool in assessing RCTs quality ${ }^{26)}$. The PEDro checklist includes eleven items in the form of 'yes' or 'no' questions. The external validity of the studies is questioned in the first item; however, this item is not used in calculating the final score. As stated by the PEDro guidelines, criteria 2 through 11 are used for scoring purposes so that the obtained score ranges between 0 and $10^{26}$. A study was considered a high quality study if the PEDro score was 6 or above, but if the score was less than 6 it was considered as low quality ${ }^{27}$. The following types of bias are assessed in PEDro checklist: selection bias, performance bias and detection bias $^{27)}$.

The standardised JBI-MAStARI data extraction form was used by the two independent reviewers (A.I. \& N.A.) to extract the data. The studies' design, population, sample size, interventions and primary outcome measures were recorded. Discrepancies were managed by a consensus. A third reviewer (C.M.) was approached in cases where no consensus was reached. Included studies were expected to exhibit high levels of heterogeneity; hence, the results analysis did not implement statistical pooling of the results. According to van Tulder et al. ${ }^{28)}$, it is not applicable to implement a quantitative analysis if the included studies were clinically heterogeneous. Therefore, a narrative synthesis was completed by accrediting levels that rate the clinical evidence. The Grading of Recommendations, Assessment, Development and Evaluations (GRADE) was used for the quality evaluation across the included studies. This approach assesses specific clinical outcomes across the review trials: methodological defects within the constituent studies, consistency of results across the trials, generalisability of research results to the wider population and how effective were the treatments. The overall quality of the evidence is given one of four GRADE scores: high (at least 4 points overall), moderate (3 points), low (2 points), and very low (one or less) ${ }^{29}$.

\section{RESULTS}

A total of 28 records were identified. Searching the reference lists generated one additional study to the electronic database search. After assessing eligibility criteria, six studies were retained for full-text review; only four studies were included in the review, which have met all the eligibility criteria (Fig. 1). Comprehensive information about the PEDro scores for the four studies included is outlined (Table 1). Scores range from 7 to 8 with a modal score of 7 out of 10 points (good methodological quality). Three of the studies have scored $7 / 10^{18-20)}$ and one has scored $8 / 10^{30}$ ). Among the four trials, the most frequently neglected items were: the blinding of subjects ( 3 studies) and therapists ( 3 studies), and measuring at least a key outcome in more than $85 \%$ of subjects initially allocated to groups in the trials ( 3 studies) (Table 1$)$.

The total number of adult participants in the review was 665 subjects. The majority of the participants were female (female $=71.13 \%$, male $=28.87 \%$ ). All the subjects included had been diagnosed with KOA (unilateral or bilateral): the Kellgren-Lawrence score was used for the radiographic assessment and reported knee pain in most days in the month preceding the intervention was the symptom implied for clinical evaluation. In addition to the previous criteria, one study ${ }^{20)}$ had $^{2}$ inclusion criteria of including only overweight \& obese (BMI $\geq 25$ and $\leq 42)$ subjects to the trial. One study ${ }^{30}$ was limited to subjects who met the insomnia disorder criteria $^{33}$. The trials included are summarised in (Table 2).

The intervention for KOA pain management was under the umbrella of cognitive therapy: CBT, CBT for insomnia, and PCST. However, each of the four included studies had a different protocol in providing the cognitive therapy. On average, the session duration lasted for 62 minutes, delivered on a weekly or biweekly basis. In addition, two studies had examined the effect of PCST independently and PCST combined with other interventions: behavioural weight management and exercise (i.e. Somers et al., 2012 and Bennell et al., 2016). The psychological interventions were delivered by expert psychologists in almost all four studies with a few exceptions in two of the studies. For instance, in Bennell et al.'s ${ }^{19)}$ RCT, PCST was delivered by physical therapists who had undergone extensive training by two psychologists. For treatment fidelity for PCST, some psychologists have randomly selected $10 \%$ of the sessions' audiotapes to assess the quality of the delivered intervention. Furthermore, in Helminen et al.'s ${ }^{18)}$ RCT, physical therapists cooperated with psychologists in providing the intervention. Where physical therapists' role was to lead the relaxation exercises, to facilitate the group, to educate the patients about the mechanism of OA pain in the first session, and to advise the subjects about suitable exercises in the second session.

The selected outcome measure from the various measures reported in the four studies was the WOMAC pain subscale. The score in this subscale ranges between 0 and 20. However, the common method of measurement is 0 to 100 scale. Table 3 depicts the findings for the outcome measure across the studies. Participants' dropout was reported in all studies and the reasons for dropout were reported in detailed flowchart in each study. Importantly, the four studies had adhered to the intent to treat principle. The highest dropout of participants among the included studies was reported in Somers et al.'s RCT ${ }^{20)}$; only $70 \%$ of participants completed the 2 year study. The number of participants who completed the study is [47 (76\%); $39(65 \%)$; 40 (68\%); and $37(73 \%)$ ] in the following groups PCST \& BWM, PCST, BWM and standard care respectively. However, 


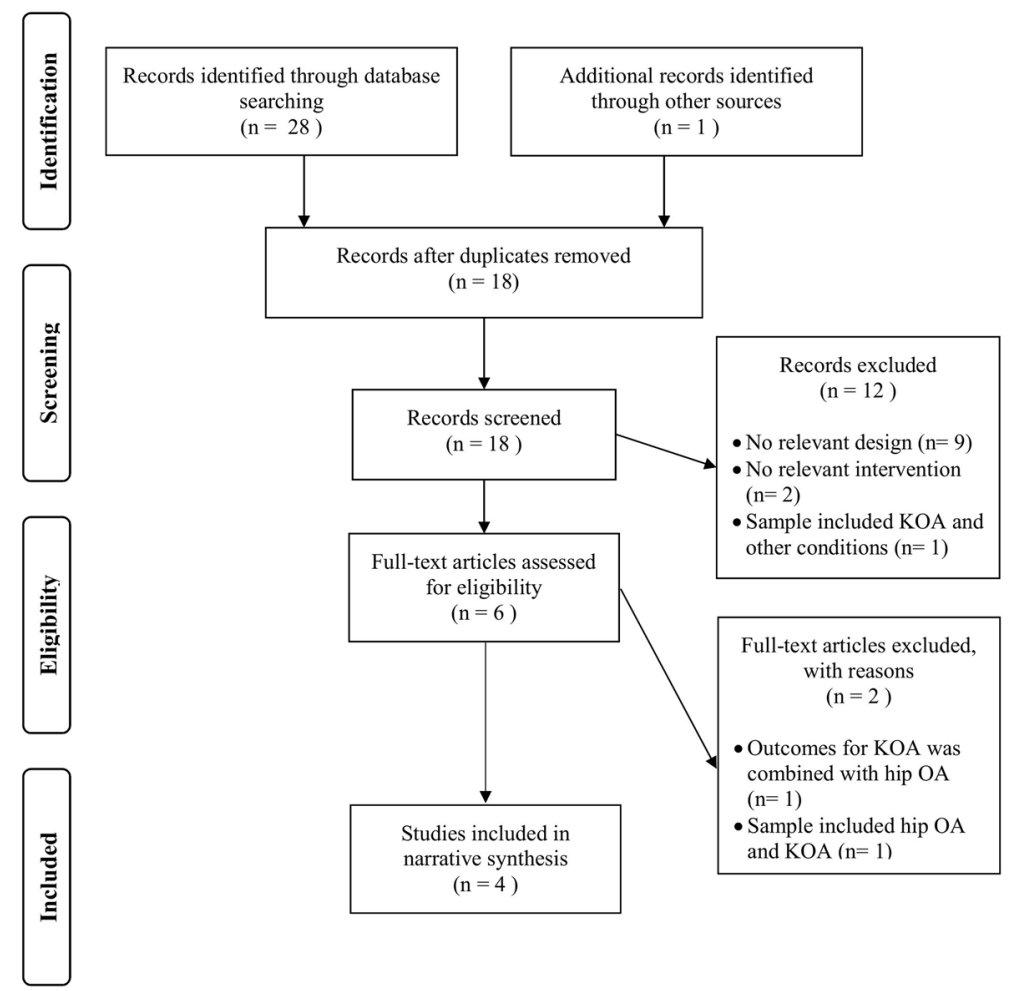

Fig. 1. PRISMA flowchart of study selection.

Table 1. PEDro score for each included studies

\begin{tabular}{|c|c|c|c|c|c|c|c|c|c|c|c|c|}
\hline \multirow[t]{2}{*}{ Study } & \multicolumn{11}{|c|}{ Items of PEDro score } & \multirow[t]{2}{*}{ Total score } \\
\hline & 1 & 2 & 3 & 4 & 5 & 6 & 7 & 8 & 9 & 10 & 11 & \\
\hline Somers et al., 201220) & + & + & + & + & - & - & + & - & + & + & + & $7 / 10$ \\
\hline Helminen et al., 2014 ${ }^{18)}$ & + & + & + & + & - & - & - & + & + & + & + & $7 / 10$ \\
\hline Smith et al., 2015 30) & + & + & - & + & + & + & + & - & + & + & + & $8 / 10$ \\
\hline Bennell et al., 2016 ${ }^{19)}$ & + & + & + & + & - & - & + & - & + & + & + & $7 / 10$ \\
\hline \multicolumn{13}{|l|}{ Item criteria } \\
\hline $\begin{array}{l}\text { 1. Eligibility criteria wer } \\
\text { 2. Subjects were random } \\
\text { 3. Allocation was concea } \\
\text { 4. The groups were simil } \\
\text { 5. There was blinding of } \\
\text { 6. There was blinding of } \\
\text { 7. There was blinding of } \\
\text { 8. Measures of at least or } \\
\text { 9. Intention to treat. } \\
\text { 10. The results of betwee } \\
\text { 11. The study provides b }\end{array}$ & $\begin{array}{l}\text { ecif } \\
\text { loca } \\
\text { tbas } \\
\text { ubj } \\
\text { her } \\
\text { isses } \\
\text { ey o } \\
\text { oup }\end{array}$ & $\begin{array}{l}\text { s w } \\
\text { me } \\
\text { misti }\end{array}$ & $\begin{array}{l}\text { mi } \\
\text { asu } \\
\text { obt }\end{array}$ & $\begin{array}{l}\text { red } \\
\text { at le } \\
\text { d fr } \\
\text { ons }\end{array}$ & $\begin{array}{l}\text { her } \\
\text { ne } \\
\text { nor } \\
\text { epc }\end{array}$ & $\begin{array}{l}\text { utc } \\
85 \\
\text { for }\end{array}$ & the & $\begin{array}{l}\text { ject } \\
\text { ey }\end{array}$ & iall & oca & o gr & \\
\hline
\end{tabular}

intention to treat analysis was implied and the dropout rates did not significantly vary across treatment conditions.

A narrative synthesis of data was performed due to nonfulfillment of the meta-analysis conditions (i.e. same intervention administered in the same way) ${ }^{34)}$. The overall level of evidence of this review is 2 (low evidence). Based on these results, CBT and PCST still cannot be recommended as a sole intervention for managing KOA pain provided there was statistical evidence of lack of improvement in the WOMAC pain index. Even though reduction in WOMAC pain score from baseline to certain follow-up points was reported in some studies, that difference was statistically insignificant (Smith et al. in Table 4). 
Table 2. Characteristics of included studies

\begin{tabular}{|c|c|c|c|c|c|c|}
\hline Citation & $\begin{array}{l}\text { Effect } \\
\text { name }\end{array}$ & Participants & Total N & Intervention group & Comparison group(s) & $\begin{array}{c}\text { Follow up } \\
\text { period }\end{array}$ \\
\hline $\begin{array}{l}\text { Somers } \\
\text { et al., } \\
2012^{20)}\end{array}$ & PCST & $\begin{array}{l}\text { Adults ( } 20-85 \text { years); } \\
\text { Overweight or obese } \\
\text { (BMI } \geq 25 \text { and } \leq 42 \text { ); knee } \\
\text { pain in the most days in the } \\
\text { prior } 6 \text { months; radiographic } \\
\text { evidence of KOA (unilateral } \\
\text { or bilateral) based on K-L } \\
\text { score }\end{array}$ & $\begin{array}{l}\mathrm{N}=232 \\
\text { PCST \& } \\
\text { BWM, } n=62 \\
\text { PCST, } n=60 \\
\text { BWM, } n=59 \\
\text { Standard care, } \\
n=51\end{array}$ & $\begin{array}{l}\text {-PCST course was deliv- } \\
\text { ered over } 24 \text { weeks. A } \\
\text { weekly session in the first } \\
12 \text { weeks. A session every } \\
\text { other week in the last } 12 \\
\text { weeks. The session dura- } \\
\text { tion is one hour. } \\
\text {-PCST \& BWM: Partici- } \\
\text { pants in this group received } \\
\text { the PCST and BWM proto- } \\
\text { cols described combined. }\end{array}$ & $\begin{array}{l}\text {-Standard care control. } \\
\text {-BWM: During the first } 12 \\
\text { weeks, one-hour of BWM } \\
\text { session was delivered weekly } \\
\text { in addition to three } 90 \text {-min- } \\
\text { ute supervised exercise } \\
\text { sessions. During the last } 12 \\
\text { weeks, only BWM sessions } \\
\text { were delivered, and it was } \\
\text { held every other week. }\end{array}$ & $\begin{array}{l}\text { 24-week } \\
6 \text {-month } \\
\text { 12-month } \\
\text { 2- years }\end{array}$ \\
\hline
\end{tabular}

\begin{tabular}{|c|c|c|c|c|c|c|}
\hline $\begin{array}{l}\text { Helmin- } \\
\text { en et al., } \\
2014^{18)}\end{array}$ & CBT & $\begin{array}{l}\text { Adults ( } 35-75 \text { years); knee } \\
\text { pain in the most days in the } \\
\text { last year; radiographic evi- } \\
\text { dence of KOA based on K-L } \\
\text { score; one week prior to the } \\
\text { study the knee pain was ( } \geq 40 \\
\text { on a } 100-\mathrm{mm} \text { ) in the pain } \\
\text { subscale of the (WOMAC) } \\
\text { index }\end{array}$ & $\begin{array}{l}\mathrm{N}=111 \\
\text { GP care \& } \\
\text { CBT, } n=55 \\
\text { GP care, } n=56\end{array}$ & $\begin{array}{l}\text { CBT was delivered over } \\
\text { a period of } 6 \text { weeks (1 } \\
\text { session/week) according } \\
\text { to Linton's model }{ }^{31} \text {. Each } \\
\text { session lasted for } 2 \text { hours } \\
\text { with a } 15-20 \text { minute break. }\end{array}$ & GP care & $\begin{array}{l}\text { 3-month } \\
12 \text {-month }\end{array}$ \\
\hline $\begin{array}{l}\text { Smith } \\
\text { et al., } \\
2015^{30)}\end{array}$ & CBT-I & $\begin{array}{l}\text { Adults (mean age }=59.2 \pm \\
9.9 \text { years); met the criteria } \\
\text { for insomnia disorder; met } \\
\text { the American College of } \\
\text { Rheumatology criteria for the } \\
\text { classification of KOA; knee } \\
\text { pain experienced } 5 \text { days/week } \\
\text { for } 6 \text { months; radiographic } \\
\text { evidence of KOA K-L score }\end{array}$ & $\begin{array}{l}\mathrm{N}=100 \\
\text { CBT-I, } \mathrm{n}=50 \\
\mathrm{BD}, \mathrm{n}=50\end{array}$ & $\begin{array}{l}\text { CBT-I was delivered in } \\
8 \text { sessions } \\
\text { ( } 45 \text { minute/session). }\end{array}$ & $\begin{array}{l}\text { Behavioural } \\
\text { desensitization } \\
\text { (active placebo) }^{32)}\end{array}$ & $\begin{array}{l}\text { Post-treat- } \\
\text { ment } \\
\text { 3-month } \\
6 \text {-month }\end{array}$ \\
\hline $\begin{array}{l}\text { Bennell } \\
\text { et al., } \\
2016^{19)}\end{array}$ & PCST & $\begin{array}{l}\text { Adults ( } \geq 50 \text { years); fulfilled } \\
\text { the American College of } \\
\text { Rheumatology criteria (pain } \\
\text { on most days in the past } \\
\text { month and radio- graphic } \\
\text { changes); knee pain } \geq 3 \\
\text { months; average pain during } \\
\text { previous week } \geq 40 \text { on } 100 \text { - } \\
\text { mm VAS; at least moderate } \\
\text { difficulty with daily activities: } \\
\text { WOMAC physical function } \\
\text { subscale } \geq 25 \text { of } 68 \text { units }\end{array}$ & $\begin{array}{l}\mathrm{N}=222 \\
\mathrm{PCST} \& \text { exer- } \\
\text { cise, } \mathrm{n}=73 \\
\text { Exercise, } \mathrm{n}=75 \\
\text { PCST, } \mathrm{n}=74\end{array}$ & $\begin{array}{l}\text {-PCST sessions ( } 10 \text { session) } \\
\text { were delivered over a 12- } \\
\text { week period } \\
\text { ( } 45 \text { minute/ session). } \\
\text {-PCST \& exercise: } \\
\text { ( } 70 \text { minute/ session). } \\
\text { Comprising } 45 \text { minutes of } \\
\text { PCST and } 25 \text { minutes of } \\
\text { exercise. }\end{array}$ & $\begin{array}{l}\text { Exercise (strengthening } \\
\text { exercises). Ten sessions over } \\
\text { a } 12 \text {-week period } \\
\text { ( } 25 \text { minute/ session). }\end{array}$ & $\begin{array}{l}\text { 12-weeks } \\
\text { 32-week } \\
52 \text {-week }\end{array}$ \\
\hline
\end{tabular}

PCST: Pain Coping Skills Training; CBT: Cognitive Behavioural Therapy; CBT-I: Cognitive Behavioural Therapy For Insomnia; BMI: Body Mass Index; K-L: Kellgren-Lawrence score; WOMAC: the Western Ontario and McMaster Universities osteoarthritis index; BWM: Behavioural Wight Management; BD: Behavioural desensitization; VAS: Visual Analog Scale.

\section{DISCUSSION}

The objective of this review was to assess the effectiveness of CBT and PCST in managing the level of perceived KOA pain systematically. Four studies met the inclusion criteria. Regardless of the variations in the protocols followed in the four studies, the findings were consistent regarding no statistically significant difference in the WOMAC pain index in terms of providing CBT or PCST only to KOA patients. However, significant differences were reported when PCST was combined with other interventions (Table 4) ${ }^{19}{ }^{20}$. To explain, the success of offering PCST \& behavioural weight management (BWM) combined might be attributable to the suitability to the trail's participant: the inclusion criteria of Somers et al.'s study of including only overweight and obese subjects ${ }^{20}$. Since obesity and overweight are one of the major risk factors for $\mathrm{KOA}^{6}$ ), providing a conjoint intervention that addresses pain psychology and mechanical loading (i.e. comprehensive weight 
Table 3. Treatment outcomes according to the WOMAC pain subscale

\begin{tabular}{|c|c|c|c|c|c|c|c|}
\hline \multirow[b]{2}{*}{ Study } & \multirow[b]{2}{*}{ Intervention } & \multicolumn{3}{|c|}{ Mean difference } & \multirow[b]{2}{*}{$\begin{array}{l}\% \text { Change } \\
\text { from baseline }\end{array}$} & \multirow[b]{2}{*}{ Effect size } & \multirow[b]{2}{*}{ MCII achieved } \\
\hline & & $\begin{array}{l}\text { Pre-treatment } \\
\text { (SD) }\end{array}$ & $\begin{array}{c}\text { 12-month } \\
\text { Post-treatment } \\
\text { (SD) except }\end{array}$ & $\begin{array}{l}\text { Between } \\
\text { groups }\end{array}$ & & & \\
\hline \multirow{4}{*}{$\begin{array}{l}\text { Somers et al., } \\
2012^{20)}\end{array}$} & PCST +BWM & $47.7(22.5)$ & $27.2(13.05)$ & -20.5 & $-43 \%$ & $0.77 \$$ & Yes \\
\hline & PCST only & $42.8(20.16)$ & $34.5(14.62)$ & -8.3 & $-19.4 \%$ & 0.25 & No \\
\hline & BWM only & $42.6(19.2)$ & $35.5(13.9)$ & -0.71 & $-16.7 \%$ & 0.18 & No \\
\hline & Standard care* & $43.3(22.04)$ & $38.0(14.03)$ & -5.3 & $-12.2 \%$ & - & No \\
\hline \multirow{2}{*}{$\begin{array}{l}\text { Helminen et al., } \\
2014^{18)}\end{array}$} & CBT & $57.6(13.4)$ & $35.6(20.2)$ & -22 & $-38.2 \%$ & 0.18 & Yes \\
\hline & GP care* & $56.4(13.6)$ & $39.5(22.0)$ & -16.9 & $-30 \%$ & - & No \\
\hline \multirow{2}{*}{$\begin{array}{c}\text { Smith et al., } \\
2015^{30)}\end{array}$} & CBT-I & $46.5(20)$ & $40.3(23.8)$ ฯ & -6.2 & $-13.3 \%$ & 0.18 & No \\
\hline & $\mathrm{BD}^{*}$ & $49.7(24.5)$ & $35.4(27.5) \rrbracket$ & -14.3 & $-28.8 \%$ & - & No \\
\hline \multirow{3}{*}{$\begin{array}{l}\text { Bennell et al., } \\
2016^{19)}\end{array}$} & PCST +exercise & $45(14)$ & $26(16.5)$ & -19 & $-42.2 \%$ & 0.06 & Yes \\
\hline & PCST only & $43.5(14)$ & $29(15)$ & -14.5 & $-33 \%$ & 0.12 & No \\
\hline & Exercise only* & $43(13.5)$ & $27(17)$ & -16 & $-37.2 \%$ & - & No \\
\hline
\end{tabular}

Mean difference score calculated according to (0-100) scale. MICC: Minimally Clinically Important Improvement in WOMAC pain subscale [ $-40.8 \%$ or -19.9 scale]; $\uparrow$ Post-treatment average after 6-month follow-up time point; * Control group for effect size; \$ considered a $>0.75$ moderate to large effect; WOMAC: the Western Ontario and McMaster Universities osteoarthritis index; PCST: Pain Coping Skills Training; BWM: Behavioural Wight Management; CBT: Cognitive Behavioural Therapy; CBT-I: Cognitive Behavioural Therapy For Insomnia; BD: Behavioural desensitization; CMD: Clinically meaningful difference.

Table 4. Summary of statistical findings

\begin{tabular}{lll}
\hline Study & Summary of findings & Reviewer comment \\
$\begin{array}{l}\text { Somers } \\
\text { et al., }\end{array}$ & $\begin{array}{l}\text { The PCST \& BWM group scored the lowest post-treatment score in the WOMAC } \\
\text { pain subscale when compared to the other three groups. That was followed by PCST, } \\
\text { then BWM and finally standard care. PCST \& BWM differed significantly from } \\
\text { BWM-only, PCST-only, and standard care, p value=0.002; } 0.01 ; 0.0002 \text { respectively. }\end{array}$ & $\begin{array}{l}\text { The value of comparing PCST-only } \\
\text { with BWM-only and standard care } \\
\text { were not reported. }\end{array}$ \\
\hline $\begin{array}{l}\text { Helminen } \\
\text { et al., }\end{array}$ & $\begin{array}{l}\text { The WOMAC pain score was slightly lower in the intervention group than the control } \\
\text { at the two follow up points. No significant difference was found for pain in } \\
\text { comparing the effect of CBT and GP care with the GP care only (p value=0.332). }\end{array}$ & $\begin{array}{l}\text { blinding items (i.e. subjects, thera- } \\
\text { pist, and assessor) in performing the } \\
\text { RCT. }\end{array}$ \\
$\begin{array}{lll}\text { Smith } \\
\text { et al., }\end{array}$ & $\begin{array}{l}\text { The WOMAC pain subscale decreased from baseline to the 6-month assessment in } \\
\text { all patients (p>0.001). No statistical difference between CBT-I and BD at 6-month } \\
\text { 2015 }\end{array}$ & $\begin{array}{l}\text { Intervention and placebo not fully } \\
\text { described. }\end{array}$
\end{tabular}

Bennell PCST \& exercise was more efficacious than PCST only at the 12-week and 32-week et al., follow up $(\mathrm{p}<0.01)$ and $(\mathrm{p}<0.05)$ respectively.

The p value of comparing PCST-only with exercise was not reported.

management program) can have a positive impact on reducing knee pain level. Similarly, the combination of PCST with exercise was more efficacious than PCST only $(\mathrm{P}<0.01 ; \mathrm{P}<0.05)$ at the two assessment follow up time points $(12$-weeks and 32-weeks) respectively ${ }^{19}$. Hence, PCST can be suggested as an augmenting tool in KOA rehabilitation. Moreover, it is important to note that in both trials that provided combined PCST interventions, a home-based practice during the follow-up period was given to the intervention group. That suggests the importance of life-style modification for KOA patients.

Effect sizes were inferred as 0.2 (small), 0.5 (medium), and 0.8 (large $)^{35)}$. Only Somers et al.'s study that provided PCST combined with BWM intervention had attained a moderate to large effect size $(0.77)^{20)}$. In other words, KOA patients who receive PCST with BWM for pain management are 69\% more likely to have a reduction in pain than patients who get standard care only ${ }^{36}$ ). The other intervention groups in the review had small effect sizes (ranged from 0.06 to 0.25 ) when compared to control groups (Table 3). Jones et al. claim that the effects of rehabilitation interventions, which reduce disability considerably, are significantly smaller than those of arthroplasty ${ }^{37)}$. Moreover, larger samples are usually required in order to detect small effects in clinical studies.

Although all studies' showed no statistical significance for pain outcome according to the entitled psychological interventions except when delivered with adjunct rehabilitation intervention, the clinical significance value for the WOMAC pain subscale $(-40.8 \%$ or $-19.9 \mathrm{~mm})$ has been achieved in three of the included studies. Helminen et al. CBT intervention group 
scored a difference of $-22 \mathrm{~mm}$ when compared to the control group. Furthermore, Somers et al. and Bennell et al. studies' depict clinically important improvement when PCST intervention was combined with BWM (-43\%) and with exercise $(-42.2 \%)$ respectively. However, CBT-I implied in Smith et al.'s RCT have revealed neither statistical nor clinical significance for pain (Table 3).

In regards to CBT-I, the mechanism of altering the symptomatic pain is consecutive to modulation of sleep disruption, thus, the primary focus of Smith et al.'s RCT was to assess sleep related outcomes that might have an impact on KOA pain (secondary outcome $)^{30)}$. Even though CBT-I was efficacious in improving sleep, yet the impact on pain was not significant. Moreover, Smith et al. post-treatment measures (i.e. mean, standard deviation, and effect size) were assessed at 6-month follow-up time point in contrast to the other three studies (12-month). That raise the issue of how much a psychological intervention needs after it is taught in order to produce a change in pain perception.

The quality rating of the trials was primarily influenced by not fulfilling the blinding criteria. Even though it is a critical feature in RCTs and the failure to meet these criteria affects the overall estimate of an intervention, blinding subjects and therapists in such interventions is almost unfeasible. Boutron et al. concurred that blinding of therapists, assessors and subjects in non-pharmacological treatments is harder to implement compared to the pharmacological interventions ${ }^{38)}$. Nevertheless, assessor blinding was manageable in three studies; since the assessment of pain was a set of closed-ended questions the allocated assessors could be blinded to group allocation.

Several factors might have affected this SR findings. First, a meta-analysis was not applicable in this review due to the clinical and statistical heterogeneity across the selected studies in terms of variance in the intervention protocols implied and the differences in the follow up time points. A second limitation was the evaluation of a single outcome measure (i.e. pain level) for the intervention. Even though the WOMAC index was a relevant, valid and reliable measure for assessing pain level in $\mathrm{KOA}^{25)}$, considering other measures that are mostly to be influenced by the psychological interventions, such as pain coping, depression, and psychological functioning might be relevant too. Most of the studies that have had a psychological intervention applied for chronic musculoskeletal conditions have measured some or all of the previously mentioned outcomes. However, there is a possibility of reporting bias when the authors focus only on non-pain outcomes that have a robust estimate of improvement. Yet, these improvements might have an indirect impact on pain perception. According to Truchon ${ }^{12)}$, the relationship between the effect of emotional and behavioural responses to pain and the biological responses to pain is bidirectional. In other words, the biological improvements of the somatic structures have a positive impact on behaviour and emotions towards the pain, and vice versa.

Thirdly, though the systematic search done in this review was conducted across five relevant electronic databases to the condition and the intervention, unpublished studies (i.e. guidelines, protocols, and grey literature) were not included in the review in the purpose to avoid any risk of publication bias ${ }^{39)}$. Fourthly, the search was limited to English language studies only. Lastly, a single researcher carried out the primary database search independently due to time factors, and that might have a risk of potential selection ${ }^{40}$. A more rigorous search would have been achieved if another researcher participated in that stage. To overcome this potential risk, the author used some of the keywords implied in Dixon et al.'s SR ${ }^{16)}$.

In conclusion, four studies were included in this SR, comparing the effect of CBT and PCST with usual care (i.e. GP care, exercise and weight management), placebo and/or the combination with usual care. Almost all the findings of the studies were consistent in terms of the insignificant statistical difference on pain between the psychological interventions when provided alone and the comparison groups. However, some studies have inferred that CBT and PCST combined with BWM or exercise were inducing a clinically important difference in the WOMAC pain subscale when compared to usual care. Therefore, we cannot recommend the application of CBT and PCST as a sole intervention in managing KOA pain. Future studies with rigorous methodological quality are needed to investigate the effect of mutual CBT and PCST protocols on KOA pain and pain-related functional and psychological abilities.

\section{REFERENCES}

1) NICE C: Osteoarthritis care and management in adults. London: National Institute for Health and Care Excellence, 2014.

2) Murphy L, Schwartz TA, Helmick CG, et al.: Lifetime risk of symptomatic knee osteoarthritis. Arthritis Rheum, 2008, 59: 1207-1213. [Medline] [CrossRef]

3) Johnson VL, Hunter DJ: The epidemiology of osteoarthritis. Best Pract Res Clin Rheumatol, 2014, 28: 5-15. [Medline] [CrossRef]

4) Urwin M, Symmons D, Allison T, et al.: Estimating the burden of musculoskeletal disorders in the community: the comparative prevalence of symptoms at different anatomical sites, and the relation to social deprivation. Ann Rheum Dis, 1998, 57: 649-655. [Medline] [CrossRef]

5) Silman A, Hochberg M: Epidemiology of the rheumatic diseases, 2nd ed. New York: Oxford University Press, 2001.

6) Zhang Y, Jordan JM: Epidemiology of osteoarthritis. Clin Geriatr Med, 2010, 26: 355-369. [Medline] [CrossRef]

7) Guccione AA, Felson DT, Anderson JJ, et al.: The effects of specific medical conditions on the functional limitations of elders in the Framingham Study. Am J Public Health, 1994, 84: 351-358. [Medline] [CrossRef]

8) White DK, Niu J, Zhang Y: Is symptomatic knee osteoarthritis a risk factor for a trajectory of fast decline in gait speed? Results from a longitudinal cohort study. Arthritis Care Res (Hoboken), 2013, 65: 187-194. [Medline] [CrossRef]

9) Kittelson AJ, George SZ, Maluf KS, et al.: Future directions in painful knee osteoarthritis: harnessing complexity in a heterogeneous population. Phys Ther, 2014, 94: 422-432. [Medline] [CrossRef] 
10) Katz PP, Yelin EH: Life activities of persons with rheumatoid arthritis with and without depressive symptoms. Arthritis Care Res, 1994, 7: 69-77. [Medline] [CrossRef]

11) Steultjens MP, Dekker J, Bijlsma JW: Coping, pain, and disability in osteoarthritis: a longitudinal study. J Rheumatol, 2001, 28: 1068-1072. [Medline]

12) Truchon M: Determinants of chronic disability related to low back pain: towards an integrative biopsychosocial model. Disabil Rehabil, 2001, 23: $758-767$. [Medline] [CrossRef]

13) National Collaborating Centre for Chronic Conditions (Great Britain) and National Institute for Clinical Excellence (Great Britain): Osteoarthritis: national clinical guidelines for care and management in adults. Royal College of Physicians, 2008.

14) Deshpande BR, Katz JN, Solomon DH, et al.: Number of persons with symptomatic knee osteoarthritis in the United States: impact of race/ethnicity, age, sex, and obesity. Arthritis Care Res (Hoboken), 2016, 68: 1743-1750. [Medline] [CrossRef]

15) Beswick AD, Wylde V, Gooberman-Hill R, et al.: What proportion of patients report long-term pain after total hip or knee replacement for osteoarthritis? A systematic review of prospective studies in unselected patients. BMJ Open, 2012, 2: e000435. [Medline] [CrossRef]

16) Dixon KE, Keefe FJ, Scipio CD, et al.: Psychological interventions for arthritis pain management in adults: a meta-analysis. Health Psychol, 2007, 26: 241-250. [Medline] [CrossRef]

17) Morley S, Eccleston C, Williams A: Systematic review and meta-analysis of randomized controlled trials of cognitive behaviour therapy and behaviour therapy for chronic pain in adults, excluding headache. Pain, 1999, 80: 1-13. [Medline] [CrossRef]

18) Helminen EE, Sinikallio SH, Valjakka AL, et al.: Effectiveness of a cognitive-behavioural group intervention for knee osteoarthritis pain: a randomized controlled trial. Clin Rehabil, 2015, 29: 868-881. [Medline] [CrossRef]

19) Bennell KL, Ahamed Y, Jull G, et al.: Physical therapist-delivered pain coping skills training and exercise for knee osteoarthritis: randomized controlled trial Arthritis Care Res (Hoboken), 2016, 68: 590-602. [Medline] [CrossRef]

20) Somers TJ, Blumenthal JA, Guilak F, et al.: Pain coping skills training and lifestyle behavioral weight management in patients with knee osteoarthritis: a randomized controlled study. Pain, 2012, 153: 1199-1209. [Medline] [CrossRef]

21) Moher D, Liberati A, Tetzlaff J, et al. PRISMA Group: Preferred reporting items for systematic reviews and meta-analyses: the PRISMA statement. Ann Intern Med, 2009, 151: 264-269, W64. [Medline] [CrossRef]

22) McConnell S, Kolopack P, Davis AM: The Western Ontario and McMaster Universities Osteoarthritis Index (WOMAC): a review of its utility and measurement properties. Arthritis Rheum, 2001, 45: 453-461. [Medline] [CrossRef]

23) Anderson JJ, Felson DT, Meenan RF, et al.: Which traditional measures should be used in rheumatoid arthritis clinical trials? Arthritis Rheum, 1989, 32: 1093-1099. [Medline] [CrossRef]

24) Katz PP, Pasch LA, Wong B: Development of an instrument to measure disability in parenting activity among women with rheumatoid arthritis. Arthritis Rheum, 2003, 48: 935-943. [Medline] [CrossRef]

25) Salaffi F, Leardini G, Canesi B, et al. GOnorthrosis and Quality Of Life Assessment (GOQOLA): Reliability and validity of the Western Ontario and McMaster Universities (WOMAC) Osteoarthritis Index in Italian patients with osteoarthritis of the knee. Osteoarthritis Cartilage, 2003, 11: 551-560. [Medline] [CrossRef]

26) Maher CG, Sherrington C, Herbert RD, et al.: Reliability of the PEDro scale for rating quality of randomized controlled trials. Phys Ther, 2003, 83: 713-721. [Medline]

27) Elkins MR, Herbert RD, Moseley AM, et al.: Rating the quality of trials in systematic reviews of physical therapy interventions. Cardiopulm Phys Ther J, 2010, 21: 20-26. [Medline]

28) van Tulder MW, Koes BW, Bouter LM: Conservative treatment of acute and chronic nonspecific low back pain. A systematic review of randomized controlled trials of the most common interventions. Spine, 1997, 22: 2128-2156. [Medline] [CrossRef]

29) Atkins D, Eccles M, Flottorp S, et al. GRADE Working Group: Systems for grading the quality of evidence and the strength of recommendations I: critical appraisal of existing approaches The GRADE Working Group. BMC Health Serv Res, 2004, 4: 38. [Medline] [CrossRef]

30) Smith MT, Finan PH, Buenaver LF, et al.: Cognitive-behavioral therapy for insomnia in knee osteoarthritis: a randomized, double-blind, active placebocontrolled clinical trial. Arthritis Rheumatol, 2015, 67: 1221-1233. [Medline] [CrossRef]

31) Linton SJ: Understanding pain for better clinical practice: a psychological perspective. China: Elsevier, 2005.

32) Lacks P, Bertelson AD, Sugerman J, et al.: The treatment of sleep-maintenance insomnia with stimulus-control techniques. Behav Res Ther, 1983, 21: 291-295. [Medline] [CrossRef]

33) Edinger JD, Bonnet MH, Bootzin RR, et al. American Academy of Sleep Medicine Work Group: Derivation of research diagnostic criteria for insomnia: report of an American Academy of Sleep Medicine Work Group. Sleep, 2004, 27: 1567-1596. [Medline] [CrossRef]

34) Munn Z, Tufanaru C, Aromataris E: JBI's systematic reviews: data extraction and synthesis. Am J Nurs, 2014, 114: 49-54. [Medline] [CrossRef]

35) Cohen J: Statistical power analysis for the behavioral sciences (Revised ed.). New York: Academic Press, 1977.

36) Coe R: It's the effect size, stupid: What effect size is and why it is important. 2002.

37) Jones CA, Voaklander DC, Johnston DW, et al.: Health related quality of life outcomes after total hip and knee arthroplasties in a community based population. J Rheumatol, 2000, 27: 1745-1752. [Medline]

38) Boutron I, Tubach F, Giraudeau B, et al.: Blinding was judged more difficult to achieve and maintain in nonpharmacologic than pharmacologic trials. J Clin Epidemiol, 2004, 57: 543-550. [Medline] [CrossRef]

39) Rothstein HR, Sutton AJ, Borenstein M: Publication bias in meta-analysis: prevention, assessment and adjustments. Chichester: John Wiley \& Sons, 2006.

40) Berger VW: Quantifying the magnitude of baseline covariate imbalances resulting from selection bias in randomized clinical trials. Biom J, 2005, 47: 119-127, discussion 128-139. [Medline] [CrossRef] 